\title{
Patterns of loss of heterozygosity in breast carcinoma during neoadjuvant chemotherapy
}

\author{
CLAIRE OUDIN $^{1}$, FRANK BONNETAIN ${ }^{2}$, ROMAIN BOIDOT $^{1}$, \\ FRÉDÉRIQUE VÉGRAN ${ }^{1}$, MARIE-SOPHIE SOUBEYRAND ${ }^{3}$, LAURENT ARNOULD ${ }^{3}$, \\ JEAN-MARC RIEDINGER $^{4}$ and SARAB LIZARD-NACOL ${ }^{1}$ \\ ${ }^{1}$ Laboratory of Molecular Genetics, ${ }^{2}$ Department of Medical Information, ${ }^{3}$ Laboratory of Pathology, \\ ${ }^{4}$ Laboratory of Medical Biology, Centre Georges François Leclerc, INSERM U-517, Dijon, France
}

Received December 21, 2006; Accepted February 19, 2007

\begin{abstract}
There is evidence indicating that resistance to some chemotherapy drugs is related to enhanced repair of DNA lesions. Microsatellite instability (MSI) and loss of heterozy-gosity (LOH) reflect genetic instability and are associated with specific DNA repair pathways. Despite the strong implication of genetic instability in breast cancer its association with chemotherapy is unknown. Thus, we analyzed microsatellite alterations with 12 markers in locally advanced breast carcinomas in relation to neoadjuvant epirubicin-cyclophosphamide-containing chemotherapy (FEC-100) and compared it to a docetaxol-based (Tax-Epi) regimen. Samples were obtained before, during and after treatments. In pre-treated samples, MSI was detected only in 2 cases $(7 \%)$ whereas $\mathrm{LOH}$ was found in 23 of the 34 (68\%) carcinomas including 10 belonging to the FEC-100 group and 13 to Tax-Epi one. LOH frequency decreased from the first course of both regimens, but differences between the patterns of LOH during treatment were found. Persistent LOH was more frequent in FEC-100 group ( $71 \%$ vs. $41 \%$ ) that was detected only in biopsies belonging to nonresponder patients. Persistent $\mathrm{LOH}$ were clustered at particular loci located at regions containing common fragile sites (FHIT and FRA6E). Analysis of baseline LOH with 6 markers located at $3 p$ indicates discontinuous patterns reflecting double-strand break (DSB) lesions. These results agree with a drug-dependent link between genetic instability and chemoresistance and show that FEC-100 treatment is associated with DSB accumulation manifested as LOH in tumor cells resistant to chemotherapy in breast carcinoma.
\end{abstract}

Correspondence to: Dr Sarab Lizard-Nacol, Laboratory of Molecular Genetics, Centre Georges François Leclerc, 1 rue du Professeur Marion, 21034 Dijon Cedex, France

E-mail: slizard@dijon.fnclcc.fr

Key words: breast cancer, double strand breaks, loss of heterozygosity, neoadjuvant chemotherapy

\section{Introduction}

Breast cancer is characterized by genomic instability, which includes amplification of proto-oncogenes, loss of heterozygosity (LOH) and microsatellite instability (MSI). Normally, genomic stability is maintained through error-free DNA replication, post-replicative proof-reading, DNA repair, and recombinational events. The study of hereditary non-polyposis colorectal carcinoma (HNPCC) revealed that loss of mismatch repair (MMR) gene products leads to MSI. In vitro studies have shown significant associations between MSI and drug resistance $(1,2)$. In addition, MSI was reported to have predictive value for survival benefit from 5-fluorouracil/ levamisol adjuvant chemotherapy in colon carcinomas $(3,4)$. However, such association has not been found in other studies $(5,6)$.

$\mathrm{LOH}$ is now recognized as an invaluable tool for cancer diagnosis and prognostication, regardless of whether the corresponding target genes have been identified. Several studies have analyzed the effect of LOH on the response to chemotherapy. $\mathrm{LOH}$ at chromosomes $9 \mathrm{p}$ and $17 \mathrm{p}$ was reported to predict low response to 5-fluorouracil/cisplatinbased neoadjuvant treatment of head and neck squamouscell carcinomas (7). Retention of heterozygosity at $17 \mathrm{p}$ or $18 \mathrm{q}$ was found to be associated with ability to benefit from adjuvant fluorouracil in colon cancer $(3,8)$. Conversely, a prognostic benefit of $\mathrm{LOH}$ at $18 \mathrm{q}$ was found with a single marker in colon cancer (8). The presence of $\mathrm{LOH}$ in the serum of patients with metastatic melanoma was associated with a poorer response to induction biochemotherapy (9). In contrast, persistence of $\mathrm{LOH}$ at 9p21 was detected in advanced pre-malignant head and neck lesions with complete clinical and histological response after 6 and 12 months cisplatin-IFN-tocopherol treatment (10). In addition, LOH at 17 p13.1 (p53 locus), as well as a high LOH frequency (estimated on different loci throughout the genome) have been associated with a better clinical response to cisplatinbased neoadjuvant chemotherapy of gastric carcinomas $(11,12)$.

Growing evidence indicates that $\mathrm{LOH}$ results from DNA double strand break (DSB) lesions (13-16). Homologous recombination and non-homologous end-joining are the two 
Table I. Microsatellite markers analyzed in this study.

\begin{tabular}{|c|c|c|c|c|}
\hline Locus & Repeat & Location & Associated gene & Primers \\
\hline BAT26 & A & $2 \mathrm{p} 22$ & hMSH2 & Kit linkage mapping set (applied) \\
\hline D3S1300 & $\mathrm{CA}$ & $3 \mathrm{p} 14.2$ & FHIT (FRA3B) & Kit linkage mapping set (applied) \\
\hline D3S1514 & GAAA & $3 \mathrm{p} 21-14.3$ & - & $\begin{array}{l}\text { GGC AAC AGA GCA AGA TGC } \\
\text { CCA GCC AGC AGA ATT ATG A }\end{array}$ \\
\hline D3S1478 & $\mathrm{CA}$ & 3p21.3-21.2 & - & $\begin{array}{l}\text { GAT GAA ACT GTG ATA GCA } \\
\text { CC CTG CCA GTA ATG TAA ATC TCC }\end{array}$ \\
\hline D3S1029 & $\mathrm{CA}$ & $3 \mathrm{p} 21.31-21.2$ & - & $\begin{array}{l}\text { ATA CTC TGG ACC CAG ATT GAT TAC } \\
\text { TAA TTC CCA AAT GGT TTA GGG GAG }\end{array}$ \\
\hline $\begin{array}{l}\text { D3S1612 } \\
-\end{array}$ & $\mathrm{CA}$ & $3 p 24-22$ & $h M L H 1$ & $\begin{array}{l}\text { TCT TTT AGT CAG CAG TTA TGT C } \\
\text { CCCATT AAG AAA TGT TAC TCT AC }\end{array}$ \\
\hline D3S1244 & CATT & $3 \mathrm{p} 24.2$ & $F A-D$ & $\begin{array}{l}\text { GTG CCC TTC CAG GAG TT } \\
\text { AGT GAG GCA TCC ACT ACC }\end{array}$ \\
\hline D6S264 & $\mathrm{CA}$ & $6 \mathrm{q} 27-25.2$ & FRA6E & Kit linkage mapping set (applied) \\
\hline D8S256 & $\mathrm{CA}$ & $8 \mathrm{q} 24.13$ & - & $\begin{array}{l}\text { GTT CAA GGG CTC AGG GTT CT } \\
\text { CTT CCA CCT TTA GCC AAG GA }\end{array}$ \\
\hline D10S197 & $\mathrm{CA}$ & $10 \mathrm{p} 11.2$ & - & Kit linkage mapping set (applied) \\
\hline TH01 & TCAT & $11 \mathrm{p} 15.5$ & $\begin{array}{l}\text { Tyrosine } \\
\text { Hydroxylase }\end{array}$ & $\begin{array}{l}\text { GTG GGC TGA AAA GCT CCC GAT TAT } \\
\text { ATT CAA AGG GTA TCT GGG CTC TGG }\end{array}$ \\
\hline D11S2179 & $\mathrm{CA}$ & $11 \mathrm{q} 23$ & ATM & $\begin{array}{l}\text { TAG GCA ATA CAG CAA GAC CCT G } \\
\text { GCA CTG GAA TAC GAT TCT AGC AC }\end{array}$ \\
\hline TP53 & $\mathrm{CA}$ & $17 \mathrm{p} 13.1$ & P53 & $\begin{array}{l}\text { ACT GCC ACT CCT TGC CCC ATT C } \\
\text { AGG GAT ACT ATT CAG CCC GAG GTG }\end{array}$ \\
\hline $\begin{array}{l}\text { TP53 } \\
\text { Penta } \\
\text { AGC }\end{array}$ & AAAAT & $17 \mathrm{p} 13.1$ & P53 & $\begin{array}{l}\text { ACT CCA GCC TGG GCA ATA AGA GCT } \\
\text { ACA AAA CAT CCC CTA CCA AAC }\end{array}$ \\
\hline D17S855 & $\mathrm{CA}$ & $17 q 21$ & $B R C A 1$ & $\begin{array}{l}\text { GGA TGG CCT TTT AGA AAG TGG } \\
\text { ACA CAG ACT TGT CCT ACT GCC }\end{array}$ \\
\hline $\mathrm{AR}$ & CAG & $\mathrm{Xq13}$ & $\begin{array}{l}\text { Androgen } \\
\text { Receptor }\end{array}$ & $\begin{array}{l}\text { TGG GGA GAA CCA TCC TCA CC } \\
\text { TCC AGA ATC TGT TCC AGA GC }\end{array}$ \\
\hline
\end{tabular}

major pathways for repairing DNA DSB in mammalian cells. DSB accumulation and overactivated recombinational repair mechanisms in tumor cells lead to resistance to many DNA damaging agents (17-19). Among the mechanisms of chemotherapy cytotoxicity (for example anthracyclines), figure the induction of DSB via the generation of reactive oxygen species (20-22). Repair of DNA crosslinks caused by crosslinking agents such as alkylating chemotherapeutic drugs (for example cyclophosphamide) is achieved by these recombinational repair mechanisms (19). The use of drugs that specifically inhibit DNA repair pathways in combination with chemotherapy has also been proposed (17-19).

In breast cancer, both anthracyclines and cyclophosphamide were used for treatment, and despite the high implication of $\mathrm{LOH}$ in this lesion its association with chemotherapy is unknown. In this study, LOH profile patterns were analyzed in breast carcinomas in relation to neoadjuvant epirubicincyclophosphamide-containing (FEC-100) chemotherapy and compared to a docetaxol-based (Tax-Epi) regimen.

\section{Materials and methods}

Patients and tumors. We studied a population of 34 patients (age 18-65 years) with non-metastatic large tumor (T2, T3N0 or T3N1), unilateral, non-inflammatory, operable breast cancer requiring mastectomy (wishing to conserve the breast) and who were treated with neoadjuvant chemotherapy at the Centre Georges François Leclerc (Dijon, France) between 1999 and 2000. Among the 34 carcinomas analyzed, 18 belong to patients who received a FEC-100 regimen (6 courses every 21 days): 5-fluorouracil $\left(500 \mathrm{mg} / \mathrm{m}^{2}\right)$, epirubicin $\left(100 \mathrm{mg} / \mathrm{m}^{2}\right)$ and cyclophosphamide $\left(500 \mathrm{mg} / \mathrm{m}^{2}\right)$. The other 16 carcinomas 

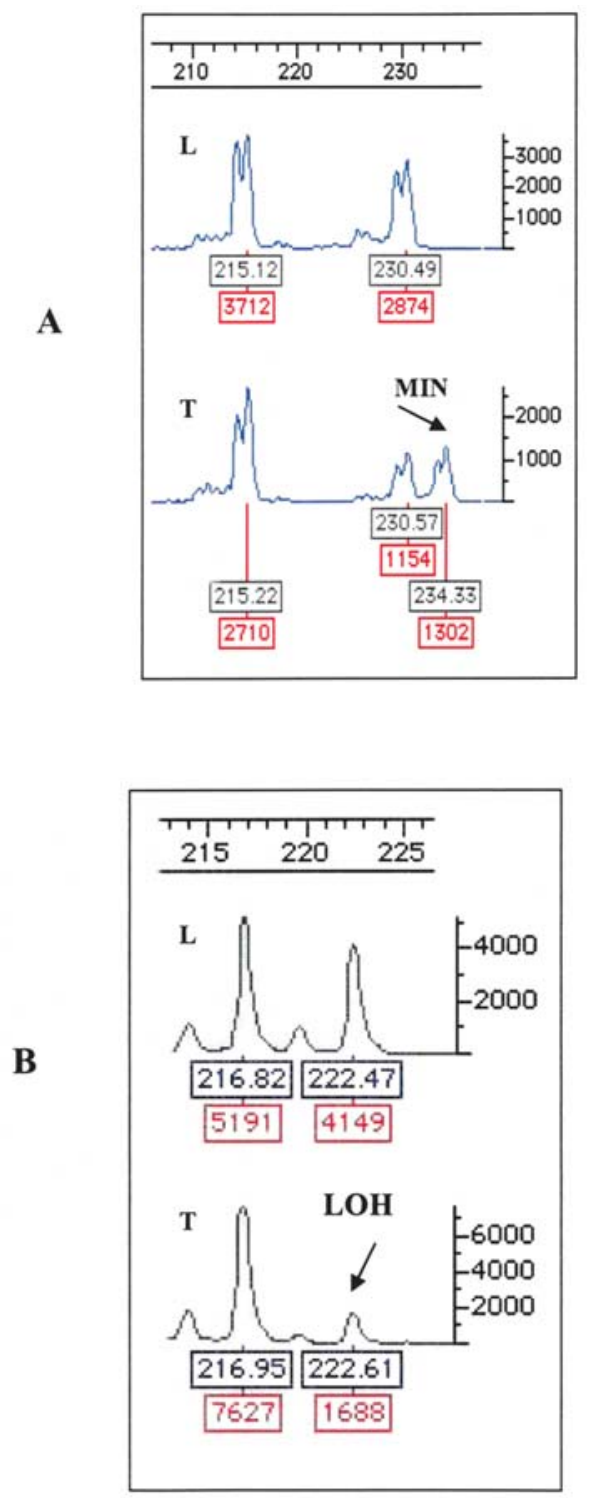

Figure 1. Representative microsatellite analysis in breast carcinoma (T) compared with their corresponding peripheral blood lymphocytes (L) MIN, microsatellite instability detected with D3S1514 marker. LOH, loss of heterozygosity obtained with AR marker.

belong to patients who received a Tax-Epi regimen ( 6 courses every 21 days): docetaxel $\left(75 \mathrm{mg} / \mathrm{m}^{2}\right)$ and epirubicin $(100 \mathrm{mg} /$ $\mathrm{m}^{2}$ ). Three biopsy specimens were analyzed for each patient corresponding respectively to 17,15 and 12 before, during and after FEC-100 treatment, whereas 13, 16 and 12 samples were analyzed before, during and after Tax-Epi treatment. Thus, a total of 85 samples were analyzed for the two treatments. Histological control for tumor cell frequencies was evaluated for each sample. All tissue samples were frozen and stored in liquid nitrogen. Blood samples were obtained from each patient, and peripheral leukocytes were used as normal controls. This work was done with the approval of the local boards governing research on human subjects.

Response evaluation. Assessment of histological response (HR) in the surgical specimens was based on a classification proposed by Sataloff et al (23). This classification allows evaluating the extent of therapeutic effect in the primary tumor site and axillary lymph nodes. HR is graded as complete if total or near total therapeutic effect on the tumor and negative nodes is present. Carcinomas are classified as partially resistant to the treatment if $>50 \%$ therapeutic effect in tumor and negative or positive nodes with therapeutic effect is present. Carcinomas are classified as resistant to the treatment if $<50 \%$ therapeutic effect in tumor, whatever the node status.

DNA isolation and microsatellite analysis. DNA extraction was performed as described previously (24). Microsatellite markers were representative of mono-, di-, tri-, tetra- and pentanucleotide repeats localized on 10 chromosome arms including: 2p, 3p, 6q, 8q, 10p, 11p, 11q, 17p, 17 and Xq. Characterization of the microsatellite markers used is reported in Table I.

The PCR products were analyzed on an ABI prism 310 automated genetic analyzer (Applied Biosystems). The data collected were further analyzed with Genescan and Genotyper softwares. Peak heights were compared between cancer and normal cells as described previously (24).

Scoring of MSI or LOH. MSI was determined by the presence of novel alleles in the tumor comparing to the corresponding normal tissue. $\mathrm{LOH}$ was determined only in cases with no evidence of MIN. Allele ratio was calculated in informative cases using peak height for each normal and tumor sample and then the normal ratio was divided by the tumor ratio as follows N2:N1/T2:T1. N2 and T2 are the height values of the longer allele product peak for the normal and tumor samples, respectively, and $\mathrm{N} 1$ and $\mathrm{T} 1$ are the height values of the shorter allele product peak for the normal and tumor samples, respectively. $\mathrm{LOH}$ was scored when allele ratios were $\leq 0.5$ or $\geq 2$. Frequency of $\mathrm{LOH}$ for each locus was calculated by dividing the number of cases presenting $\mathrm{LOH}$ by the total number of informative cases. BAT26 is a non-informative marker and was therefore not evaluated for $\mathrm{LOH}$. All suspect samples were analyzed twice by different PCR reactions.

\section{Results}

Microsatellite alterations. MSI was found in only 2 of the 34 (7\%) carcinomas with the dinucleotide repeats D3S1514 and D10S197. MSI profiles consisted in one extra allele (Fig. 1A). No MSI was detected with the mononucleotide marker BAT26. Since a very low frequency of MSI was observed, no further analysis was made for this alteration.

LOH was found in 23 of the $34(68 \%)$ carcinomas. The most frequently affected microsatellite markers in the pretherapeutic carcinomas was D3S1300 (32\%), TH01 (27\%) and TP53CA (25\%). The most affected loci for FEC-100 group were D3S1300 (45\%), TH01 (31\%) and D3S1612 (23\%), and for Tax-Epi, TP53 penta (38\%), D11S2179 (36\%) and D8S256 (33\%). The LOH was generally accumulated within the same carcinoma. For example, in the FEC-100 group, 10 of the $18(56 \%)$ patients exhibited LOH in at least one of their biopsy specimen, while no LOH was observed in the remaining 8 samples. In the Tax-Epi group, 13 of the 16 (80\%) patients had $\mathrm{LOH}$, and no $\mathrm{LOH}$ was observed in the remaining 3 samples. A representative analysis of $\mathrm{LOH}$ detection is illustrated in Fig. 1B. 

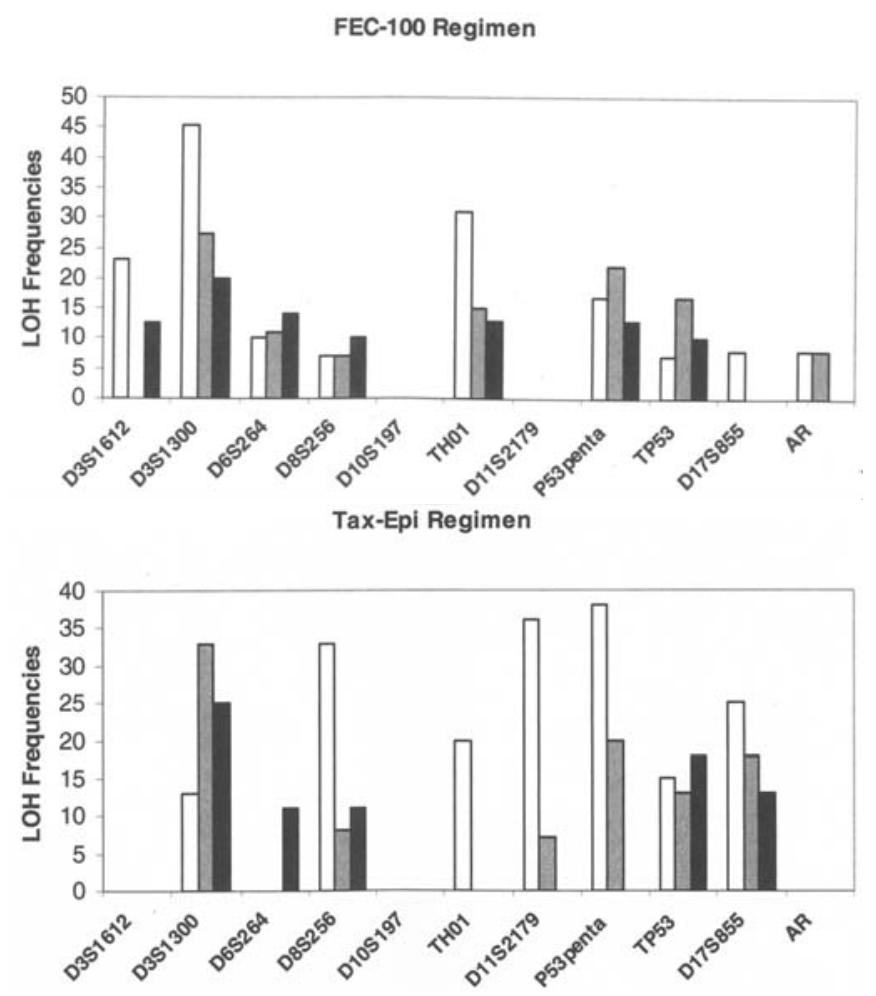

Figure 2. LOH frequencies detected before (white), during (grey) and after treatment (black) for each chemotherapy regimen.
LOH patterns during chemotherapy. The number of affected loci decreased during and after treatment for both regimens. Thus, overall LOH frequencies were 15,9 and $7 \%$, respectively before, during and after FEC-100 treatment, and a decrease from 12, to 6 to $5 \%$ was observed for Tax-Epi. However, there are differences between the patterns of $\mathrm{LOH}$ in the two groups (Fig. 2). For example, LOH at TH01, which persisted after FEC-100 treatment, disappeared from the first course of Tax-Epi, whereas LOH at D17S855 showed the opposite pattern.

Persistent LOH after chemotherapy. Although LOH frequency decreased during chemotherapy, persistent $\mathrm{LOH}$ after treatment was observed regardless of the chemotherapy regimen. For FEC-100 group, 5 of 7 cases harbored at least one persistent LOH (Table II: cases 1, 2, 3, 5 and 6). Similarly, for Tax-Epi group, 4 of 9 cases harbored at least one persistent $\mathrm{LOH}$ (Table III: cases 2, 5, 8 and 9). Thus, frequency of persistent LOH differed between the two groups $(71 \%$ and $44 \%$, respectively). In addition, persistent $\mathrm{LOH}$ in FEC group appeared closely related to the presence of viable tumor cells in post-treatment biopsy samples (Table II). In contrast, in Tax-Epi group, some LOH disappeared even in biopsies showing high fraction of viable tumor cells (cases 4, 6 and 7; Table III). Moreover, all 5 cases with persistent LOH after FEC100 chemotherapy were non-responders to the treatment. In

Table II. LOH patterns in lesion biopsy specimens taken before, during and after FEC-100 chemotherapy.

\begin{tabular}{|c|c|c|c|c|c|c|c|c|c|c|c|c|c|c|}
\hline Patient & $\begin{array}{l}\text { Time of } \\
\text { biopsy }\end{array}$ & D3S1612 & D3S1300 & D6S264 & D8S256 & D10S197 & TH01 & D11S2179 & $\begin{array}{l}\text { TP53 } \\
\text { Penta }\end{array}$ & TP53 & D17S855 & $\mathrm{AR}$ & $\mathrm{HC}$ & HR \\
\hline \multirow[t]{2}{*}{1} & Baseline & O & $\bullet S$ & $\bullet S$ & I & I & $\bullet \mathrm{L}$ & O & O & O & O & I & ND & NR \\
\hline & 6 months & O & $\bullet S$ & $\bullet S$ & I & I & O & O & O & O & O & I & ND & \\
\hline \multirow[t]{2}{*}{2} & 1 month & 1 & $\bullet S$ & $\bullet \mathrm{L}$ & $\bullet S$ & I & I & O & I & I & O & $\bullet \mathrm{L}$ & 3 & NR \\
\hline & 6 months & I & O & $\bullet \mathrm{L}$ & $\bullet S$ & I & I & O & I & I & O & O & 3 & \\
\hline \multirow[t]{3}{*}{3} & Baseline & O & $\bullet \mathrm{L}$ & I & O & O & $\bullet S$ & I & $\bullet S$ & O & O & 1 & 3 & NR \\
\hline & 1 month & O & $\bullet \mathrm{L}$ & I & O & O & $\bullet S$ & I & $\bullet S$ & $\bullet S$ & O & 1 & 2 & \\
\hline & 6 months & $\bullet S$ & O & I & O & O & O & I & $\bullet S$ & $\bullet S$ & O & 1 & 3 & \\
\hline \multirow[t]{3}{*}{4} & Baseline & $\bullet \mathrm{L}$ & I & O & O & O & O & O & I & O & O & 1 & 3 & PR \\
\hline & 1 month & O & I & O & O & O & O & O & I & O & O & 1 & 2 & \\
\hline & 6 months & O & I & O & ○ & O & O & O & I & O & O & I & 0 & \\
\hline \multirow[t]{3}{*}{5} & Baseline & I & O & I & I & I & O & O & I & O & I & ○ & 3 & NR \\
\hline & 1 month & I & O & I & I & I & O & O & I & O & I & O & 3 & \\
\hline & 6 months & I & O & I & I & I & $\bullet S$ & O & I & O & I & O & 3 & \\
\hline \multirow[t]{3}{*}{6} & Baseline & O & $\bullet \mathrm{L}$ & I & O & ○ & O & I & I & O & I & O & 3 & NR \\
\hline & 1 month & O & $\bullet \mathrm{L}$ & I & O & O & O & I & I & $\bullet S$ & I & O & 3 & \\
\hline & 6 months & O & $\bullet \mathrm{L}$ & I & O & O & O & I & I & O & I & O & 1 & \\
\hline \multirow[t]{3}{*}{7} & Baseline & $\bullet S$ & I & $\bullet S$ & O & I & O & O & $\bullet \mathrm{L}$ & O & O & $\bullet S$ & 2 & $\mathrm{CR}$ \\
\hline & 1 month & O & I & O & O & I & $\bullet \mathrm{L}$ & O & $\bullet \mathrm{L}$ & O & O & O & 3 & \\
\hline & 6 months & O & I & O & O & I & O & O & O & O & O & O & 0 & \\
\hline
\end{tabular}

- $\mathrm{LOH}$ at the shorter (S) or the longer (L) allele. O, retention of two alleles; /, not informative. ND, not determined. HC, histological control of the presence of tumor cells graded as $\geq 80 \%$ (3), $50-80 \%$ (2) or $\leq 50 \%$ (1). HR, histological response corresponding to complete (CR), partial (PR) or no response (NR). 
Table III. LOH patterns in lesion biopsy specimens taken before, during and after Tax-Epi chemotherapy.

\begin{tabular}{|c|c|c|c|c|c|c|c|c|c|c|c|c|c|c|}
\hline Patient & $\begin{array}{l}\text { Time of } \\
\text { biopsy }\end{array}$ & D3S1612 & D3S1300 & D6S264 & D8S256 & D10S197 & ТH01 & D11S2179 & $\begin{array}{l}\text { TP53 } \\
\text { Penta }\end{array}$ & TP53 & D17S855 & $\mathrm{AR}$ & $\mathrm{HC}$ & HR \\
\hline \multirow[t]{2}{*}{1} & 1 month & I & $\bullet \mathrm{L}$ & ○ & ○ & o & o & ○ & I & ○ & o & o & 0 & NR \\
\hline & 6 months & I & O & ○ & ○ & ○ & O & O & I & O & o & o & 1 & \\
\hline \multirow[t]{3}{*}{2} & Baseline & I & o & ND & ND & ND & I & ND & ND & o & ND & o & 3 & PR \\
\hline & 1 month & 1 & O & O & $\bullet S$ & O & I & O & O & O & O & O & 3 & \\
\hline & 6 months & I & O & $\bullet \mathrm{L}$ & $\bullet S$ & o & I & o & O & O & ○ & o & 3 & \\
\hline \multirow[t]{3}{*}{3} & Baseline & ND & o & ND & I & o & I & o & o & ○ & ○ & ND & 3 & $\mathrm{CR}$ \\
\hline & 1 month & O & $\bullet S$ & ○ & I & o & l & O & O & O & ○ & o & 2 & \\
\hline & 6 months & O & O & o & I & o & I & O & O & O & O & o & 1 & \\
\hline \multirow[t]{3}{*}{4} & Baseline & ○ & I & ○ & o & o & I & o & o & o & ○ & O & 3 & NR \\
\hline & 1 month & o & I & o & o & o & I & $\bullet \mathrm{L}$ & $\bullet S$ & o & o & o & 3 & \\
\hline & 6 months & o & I & ○ & ○ & o & I & o & O & o & ○ & o & 3 & \\
\hline \multirow[t]{3}{*}{5} & Baseline & o & $\bullet \mathrm{L}$ & o & I & o & o & $\bullet S$ & $\bullet \mathrm{L}$ & $\bullet S$ & I & o & 2 & NR \\
\hline & 1 month & ○ & o & ○ & I & o & O & O & $\bullet \mathrm{L}$ & O & I & O & 3 & \\
\hline & 6 months & o & $\bullet \mathrm{L}$ & o & I & o & o & O & O & $\bullet S$ & I & o & ND & \\
\hline \multirow[t]{3}{*}{6} & Baseline & I & I & ND & ND & I & o & o & $\bullet S$ & O & I & o & 0 & NR \\
\hline & 1 month & I & I & ○ & ○ & I & O & o & o & ○ & I & o & 3 & \\
\hline & 6 months & I & I & o & O & I & O & o & O & O & I & o & 3 & \\
\hline \multirow[t]{3}{*}{7} & Baseline & o & O & o & o & I & o & $\bullet \mathrm{L}$ & O & o & $\bullet S$ & o & 3 & NR \\
\hline & 1 month & ○ & $\bullet \mathrm{L}$ & ○ & o & I & o & o & O & o & ○ & o & 3 & \\
\hline & 6 months & ○ & o & ○ & ○ & I & o & O & o & O & O & o & 3 & \\
\hline \multirow[t]{3}{*}{8} & Baseline & o & o & o & ○ & I & o & o & I & $\bullet \mathrm{L}$ & $\bullet \mathrm{L}$ & o & 3 & NR \\
\hline & 1 month & ○ & ○ & ○ & ○ & I & o & O & I & $\bullet \mathrm{L}$ & $\bullet \mathrm{L}$ & o & 3 & \\
\hline & 6 months & O & O & ○ & o & I & o & o & I & $\bullet \mathrm{L}$ & $\bullet \mathrm{L}$ & o & 3 & \\
\hline \multirow[t]{3}{*}{9} & Baseline & I & o & I & ○ & o & o & o & I & O & ○ & o & 3 & PR \\
\hline & 1 month & I & o & I & ○ & O & O & o & I & $\bullet \mathrm{L}$ & $\bullet S$ & O & 2 & \\
\hline & 6 months & I & $\bullet \mathrm{L}$ & I & o & o & o & o & I & o & o & o & 2 & \\
\hline
\end{tabular}

-, $\mathrm{LOH}$ at the shorter (S) or the longer (L) allele. O, retention of two alleles; /, not informative. ND, not determined. HC, histological control of the tumor cells presence graded as $\geq 80 \%$ (3), $50-80 \%$ (2) or $\leq 50 \%$ (1). HR, histological response corresponding to complete (CR), partial (PR) or no response (NR).

Tax-Epi group, LOH pattern seemed independent from histological response status. Interestingly, persistent $\mathrm{LOH}$ was clustered at particular loci located at chromosomes $3 \mathrm{p} 14.2$ and $6 \mathrm{q} 27$.

$3 p$ region analysis. Discontinuous pattern of $\mathrm{LOH}$ was frequently observed in breast carcinomas and was attributed to interstitial deletion resulting from DSB formation $(16,25)$. To determine whether $\mathrm{LOH}$ at $3 \mathrm{p}$ observed in our study could also have a discontinuous pattern, we analyzed 4 additional microsatellite markers located in this region (Fig. 3). The results showed that the majority of cases had discontinuous $\mathrm{LOH}$ with regions of $3 p$ loss separated by intervening regions of retention of heretozygosity (example, cases $7,8,16,22)$ or $\mathrm{LOH}$ affected alternatively the shorter or the longer allele (example, nos. 2, 4, 9, 10, 11, 17). Only one case (no. 5) exhibited an eventual loss of the entire region showing $\mathrm{LOH}$ for the longer allele with the 5 markers.
In other cases (nos. 3, 18, 19), LOH affected the more telomeric loci analyzed in this study and thus the patterns could not be determined.

\section{Discussion}

Recombinational repair is an essential mechanism for the cell in order to protect its DNA from common sources of DSB, such as DNA replication and endogenous reactive oxygen species $(14,26)$. LOH constitutes a hallmark of DSB $(13,25)$, and represent the most frequent alteration detected in breast carcinoma. Our results show, for the first time, the existence of a link between LOH and chemotherapy-drugs used in breast carcinoma.

All microsatellite loci analyzed have been reported to be frequently altered in breast carcinomas except for BAT26. This is a good marker of high microsatellite instability in colon cancer and was included as an indicator of eventual 


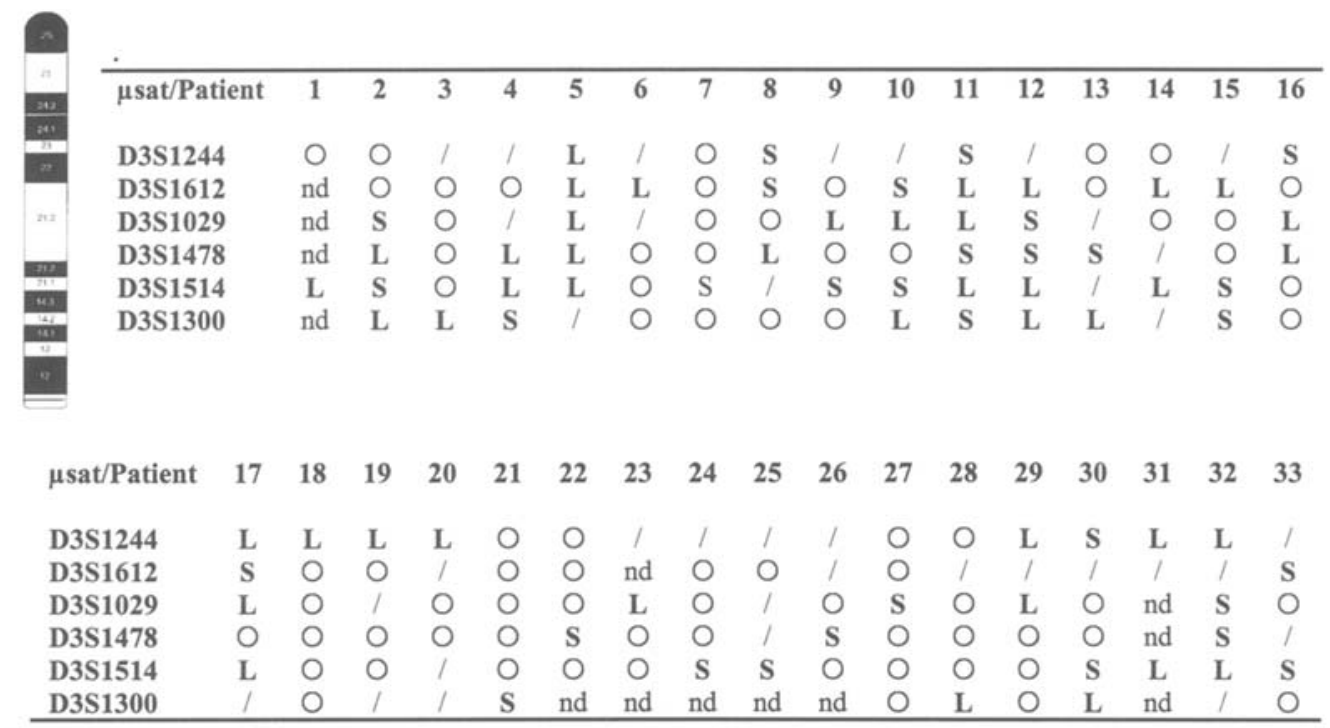

Figure 3. Chromosome 3p analysis of pre-treated breast carcinomas using 6 microsatellite markers. S, LOH at the shorter allele; L, LOH at the longer allele. 0 , retention of two alleles; /, not informative; nd, not determined.

unstable cases. In our series, MSI is a less frequent event than $\mathrm{LOH}$, and corresponds to the low frequency generally detected in breast cancer which did not fulfill the established criteria to be classified as mismatch repair deficient $(25,27-29)$. Conversely, $\mathrm{LOH}$ was found in $68 \%$ of cases, and this prevalence is in agreement with other studies $(25,29,30)$. In spite of the role that MMR genes may have in breast cancer development, MSI corresponds to a background noise of instability, of as yet unknown origin, also present in other human cancers such as gastric and head and neck squamouscell carcinomas (31). In contrast, high frequencies of LOH in individual breast carcinomas have been shown to occur non-randomly at certain chromosome loci, suggesting the involvement of specific region and regulatory genes (32).

During each treatment analyzed, LOH frequency decreased since the first course of chemotherapy. This decrease could be the result of decreasing tumor clones harboring these alterations and not a reflection of the absence of viable tumor as confirmed by the histological controls. The identical alleles affected suggested that the same tumor clones were maintained during treatments.

However, there are differences between the patterns of $\mathrm{LOH}$ in the two groups treated with different agents. In particular, persistent $\mathrm{LOH}$ appeared more frequently in the FEC-100 group. Additionally, it was detected only in posttreatment biopsies with viable tumor and non response to treatment, suggesting that persistent $\mathrm{LOH}$ after treatment could be a factor of poor prognosis following FEC-100 chemotherapy. The results indicate that clones harboring these genomic abnormalities were resistant to FEC-100, and that epirubicin-cyclophosphamide either played a role in selecting these particular clones or in inducing chromosomal instability.

Persistent LOH was clustered at particular loci located at chromosomes 3p14.2 (D3S1300) and 6q27-25 (D6S264), the region contain the FHIT and FRA6E genes, respectively. $\mathrm{LOH}$ at $3 \mathrm{p}$ is one of the frequent alterations observed in breast lesions. Located at 3p14.2, the FHIT gene encodes a protein involved in the cellular damage response, cell cycle and genetic stability regulation (33) and encom-passing the FRA3B common fragile site (34). $\mathrm{LOH}$ at 6q25.2-27 was also frequently observed in breast carcinoma. Interestingly, this locus contains the FRA6E common fragile site. It has been shown that common fragile sites exhibit increased fragility in cancer cells subjected to chemotherapy (35). Another study has also shown that DSBs are formed at these sites and that their repair was regulated by recombinational mechanisms (36).

Consistent with the above, persistent LOH in FEC-100 tumors reflects DSB accumulation and over-activated homologous recombination repair. The accumulation of DSB by Tax-Epi could be attenuated by the presence of docetaxol. Taken together, our results show that FEC-100 treatment leads to the accumulation of DSB manifested as LOH in tumor cells resistant to chemotherapy. Thus, these findings would be of great utility in the management of locally advanced breast carcinomas in order to estimate the efficacy of currently used chemotherapeutic treatments.

\section{Acknowledgments}

This work was supported by the 'Comité Départemental de Saône et Loire' and the 'Ligue Bourguignonne Contre le Cancer'. We thank Liliane Mercier and Samy-Félix Picard for their technical assistance.

\section{References}

1. Fink D, Nebel S, Norris PS, Aebi S, Kim HK and Howell SB: The effect of different chemotherapeutic agents on the enrichment of DNA mismatch repair-deficient tumour cells. Br J Cancer 77: 703-708, 1998.

2. Picard SF, Franco N, Sergent C, Chauffert B and Lizard-Nacol S: Analysis of microsatellite instability in acquired-drug resistance human tumor cell lines. Oncol Rep 9: 971-976, 2002.

3. Watanabe T, Wu TT, Catalano PJ, Ueki T, Satriano R, Haller DG, Benson AB and Hamilton SR: Molecular predictors of survival after adjuvant chemotherapy for colon cancer. $N$ Engl J Med 344: 1196-1206, 2001. 
4. Elsaleh H, Powell B, McCaul K, Grieu F, Grant R, Joseph D and Iacopetta B: P53 alteration and microsatellite instability have predictive value for survival benefit from chemotherapy in stage III colorectal carcinoma. Clin Cancer Res 7: 1343-1349, 2001.

5. Ribic MC, Sargent DJ, Moore MJ, Thibodeau SN, French AJ, Goldberg RM, Hamilton SR, Laurent-Puig P, Gryfe R, Shepherd LE, Tu D, Redston M and Gallinger S: Tumor microsatellite-instability status as a predictor of benefit from fluorouracil-based adjuvant chemotherapy for colon cancer. N Engl J Med 349: 247-257, 2003.

6. Benatti P, Gafà R, Barana D, Marino M, Scarselli A, Pedroni M, Maestri I, Guerzoni L, Roncucci L, Menigatti M, Roncari B, Maffei S, Rossi G, Ponti G, Santini A, Losi L, Di Gregorio C, Oliani C, De Leon MP and Lanza G: Microsatellite instability and colorectal cancer prognosis. Clin Cancer Res 11: 8332-8340, 2005.

7. Blons H, Cabelguenne A, Carnot F, Laccourreye O, De Waziers I, Hamelin R, Brasnu D, Beaune P and Laurent-Puig P: Microsatellite analysis and response to chemotherapy in head-andneck squamous-cell carcinoma. Int J Cancer 84: 410-415, 1999.

8. Barratt PL, Seymour MT, Stenning SP, Georgiades I, Walker C, Birbeck K and Quirke P: Adjuvant X-ray and fluorouracil infusion study. DNA markers predicting benefit from adjuvant fluorouracil in patients with colon cancer: a molecular study. Lancet 360: 1381-1391, 2002

9. Taback B, O'Day SJ, Boasberg PD, Shu S, Fournier P, Elashoff R, Wang HJ and Hoon DS: Circulating DNA microsatellites: molecular determinants of response to biochemotherapy in patients with metastatic melanoma. J Natl Cancer Inst 96: 152-156, 2004.

10. El-Naggar AK, Papadimitrakopoulou V, Shin DM, Shin HC, Fan Y, Zhou X, Clayman G, Lee JJ, Lee JS, Hittelman WN, Lippman SM and Hong WK: Phenotype and genotype of advanced premalignant head and neck lesions after chemopreventive therapy. J Natl Cancer Inst 90: 1545-1551, 1998.

11. Grundei T, Vogelsang H, Ott K, Mueller J, Scholz M, Becker K, Fink U, Siewert JR, Hofler H and Keller G: Loss of heterozygosity and microsatellite instability as predictive markers for neoadjuvant treatment in gastric carcinoma. Clin Cancer Res 6: 4782-4788, 2000

12. Ott K, Vogelsang H, Muellr J, Becker K, Muller M, Fink U, Siewert JR, Hofler H and Keller G: Chromosomal instability rather than p53 mutation is associated with response to neoadjuvant cisplatin-based chemotherapy in gastric carcinoma. Clin Cancer Res 9: 2307-2315, 2003.

13. Moynahan ME and Jasin M: Loss of heterozygosity induced by a chromosomal double-strand break. Proc Natl Acad Sci USA 94: 8988-8993, 1997

14. Pfeiffer P, Goedecke W and Obe G: Mechanisms of DNA doublestrand break repair and their potential to induce chromosomal aberrations. Mutagenesis 15: 289-302, 2000.

15. Hoeijmakers JHJ: Genome maintenance mechanisms for preventing cancer. Nature 411: 366-374, 2001.

16. Maitra A, Wistuba II, Washington C, Virmani AK, Ashfaq R, Milchgrub S, Gazdar AF and Minna JD: High-resolution chromosome $3 p$ allelotyping of breast carcinomas and precursor lesions demonstrates frequent loss of heterozygosity and a discontinuous pattern of allele loss. Am J Pathol 159: 119-130, 2001.

17. Wang ZM, Chen ZP, Xu ZY, Christodoulopous G, Bello V, Mohr G, Aloyz R and Panasci LC: In vitro evidence for homologous recombination repair in resistance to Melphalan. J Natl Cancer Inst 93: 1473-1478, 2001.

18. Hu B, Wang H, Wang X, Lu H-R, Huang C, Powell SN, Huebner $\mathrm{K}$ and Wang Y: Fhit and CHK1 have opposing effects on homologous recombination repair. Cancer Res 65: 8613-8616, 2006.

19. Kennedy RD and D'Andrea A: DNA repair pathways in clinical practice: lessons from pediatric cancer susceptibility syndromes. J Clin Oncol 4: 3799-3808, 2006.
20. Anderson RD and Berger NA: Mutagenecity and carcinogenicity of topoisomerase-interactive agents. Mutat Res 309: 109-142, 1994.

21. Froelich JJ, Schneller FR and Zahn RK: The influence of radiation and chemotherapy-related DNA strand breaks on carcinogenesis: an evaluation. Clin Chem Lab Med 37: 403-408, 1999.

22. Fojo T: Cancer, DNA repair mechanisms, and resistance to chemotherapy. J Natl Cancer Inst 93: 1434-1436, 2001.

23. Sataloff DM, Mason BA, Prestipino AJ, Seinige UL, Lieber CP and Baloch Z: Pathologic response to induction chemotherapy in locally advanced carcinoma of the breast: a determinant of outcome. J Am Coll Surg 180: 297-306, 1995.

24. Franco N, Arnould L, Mége F, Picard SF, Arveux P and LizardNacol S: Comparative analysis of molecular alterations in fibroadenomas associated or not with breast cancer. Arch Surg 138: 289-295, 2003

25. Shen CY, Yu JC, Lo YL, Kuo CH, Yue CT, Jou YS, Huang CS, Lung JC and Wu CW: Genome-wide search for loss of heterozygosity using laser capture microdissected tissue of breast carcinoma: an implication for mutator phenotype and breast cancer pathogenesis. Cancer Res 60: 3884-3892, 2000.

26. Khanna KK and Jackson SP: DNA double-strand breaks: signaling, repair and the cancer connection. Nat Genet 27: 247-254, 2001

27. Patel U, Grundfest-Broniatowski S, Gupta M and Banerjee S Microsatellite instabilities at five chromosomes in primary breast tumors. Oncogene 9: 3695-3700, 1994.

29. Dillon EK, De Boer WB, Papadimitriou JM and Turbett GR Microsatellite instability and loss of heterozygosity in mammary carcinoma and its probable precursors. Br J Cancer 76: 156-162, 1997.

28. Kasami M, Vnencak-Jones CL, Manning S, Dupont WD and Page DL: Loss of heterozygosity and microsatellite instability in breast hyperplasia. No obligate correlation of these genetic alterations with subsequent malignancy. Am J Pathol 150: 1925-1932, 1997

30. Kerangueven F, Noguchi T, Coulier F, Allione F, Wargniez V, Simony-Lafontaine J, Longy M, Jacquemier J, Sobol H, Eisinger F and Birnbaum D: Genome-wide search for loss of heterozygosity shows extensive genetic diversity of human breast carcinomas. Cancer Res 57: 5469-5474, 1997.

31. Boland R, Thibodeau SN, Hamilton SR, Idransky D, Eshleman JR, Burt RW, Meltzer SJ, Ridriguez-Bigas M, Fodde R, Ranzani GN and Srivastava S: A national cancer institute workshop on microsatellite instability for cancer detection and familial predisposition: development of international criteria for the determination of microsatellite instability in colorectal cancer. Cancer Res 58: 5248-5257, 1998

32. Thiagalingam S, Foy RL, Cheng KH, Lee HJ, Thiagalingam A and Ponte JF: Loss of heterozygosity as a predictor to map tumor suppressor genes in cancer: molecular basis of its occurrence. Curr Opin Oncol 14: 65-72, 2002.

33. Dronkert MG and Kanaar R: Repair of DNA interstrand crosslinks. Mutat Res 486: 217-247, 2001.

34. Inoue H, Ishii H, Alder H, Snyder E, Druck T, Heubner K and Croce CM: Sequence of the FRA3B common fragile region: implications for the mechanism of FHIT deletion. Proc Natl Acad Sci USA 94: 14584-14589, 1997.

35. Smith DI, Huang H and Wang L: Common fragile sites and cancer. Int J Oncol 12: 187-196, 1998.

36. Schwartz M, Zlotorynski E, Goldberg M, Ozeri E, Rahat A, Le Sage C, Chen BPC, Chen DJ, Agami R and Kerem B: Homologous recombination and non-homologous end-joining repair pathways regulate fragile site stability. Genes Dev 19: 2715-2726, 2006. 